\title{
Assessment of Nutritional Status Among Primary School Pupils in South Western Nigeria
}

\author{
Samson Ayo Deji", Oluremi Olayinka Solomon, Adebowale Femi Akinwumi, Paul Oladapo Ajayi, \\ Olusola Olugbenga Odu
}

Department of Community Medicine, Faculty of Clinical Sciences, College of Medicine, Ekiti State University, Ado Ekiti, Nigeria

Email address:

Samdeji3@hotmail.com(S. A. Deji)

*Corresponding author

\section{To cite this article:}

Samson Ayo Deji, Oluremi Olayinka Solomon, Adebowale Femi Akinwumi, Paul Oladapo Ajayi, Olusola Olugbenga Odu. Assessment of Nutritional Status Among Primary School Pupils in South Western Nigeria. Central African Journal of Public Health.

Vol. 7, No. 3, 2021, pp. 88-93. doi: 10.11648/j.cajph.20210703.11

Received: April 13, 2021; Accepted: April 29, 2021; Published: May 8, 2021

\begin{abstract}
Malnutrition remains a major problem affecting millions of children in Africa. The objective of this study was to assess the nutritional status among primary school pupils in Olorunda Local government of Osogbo metropolis in South Western Nigeria. Semi-structured questionnaires were administered to respondents in11schools randomly selected. A cross sectional study design was used and multi-stage sampling technique was utilized in selecting participants for the study. Data was analyzed using Statistical Package for the Social Sciences. A total of 487 pupils were interviewed and their age range was $5-16 y e a r s$ with a mean age of 8 years. More females (53.6\%) than males (46.4\%) were interviewed. Most fathers were skilled workers and while most mothers were in the unskilled labor force. Above half $(50.2 \%)$ of the study population were found to have poor nutritional history based on the 24 hour dietary recall. Also using WHO standard measurements of z score with a standard deviation of $<-2$, which is an indication of moderate undernourished children, $65.7 \%$ were stunted with low height for age, and $74.5 \%$ were underweight with low weight for age. More pupils were stunted in the higher classes compared to pupils in the lower classes. The study concluded that despite the various intervention programmes of non-Governmental and Governmental organizations, significant percentage of Nigerian primary school children still have poor nutritional status.
\end{abstract}

Keywords: Malnutrition, Assessment, Pupils, School, Primary

\section{Introduction}

Nutrition is a vital determinant of the state of health, growth and development of man. The nutritional status of an individual is often an offshoot of various factors which is influenced by the quality and quantity of food intake. [1] Primary school age is a critical stage of growth and development both physically and mentally for children. [2] Critical health problems arising from feeding pattern resulting in poor nutritional status among primary school age children can actually affect their classroom performance and their social life. [2] The burden of poor nutritional status is increasing in most developing countries plagued with food insecurity arising from a number of factors ranging from conflicts, inequality in the distribution of food and lack of purchasing power of quality food items. [3]
In most cases growth monitory is a simple tool to monitor the growth of children in primary schools. [4]

Nutritional assessment remains the standard measurement of assessing malnutrition which actually means undernutrition and overnutrition. In most cases undernutrition is predominant in most Asia and African continent. [5] The United Nations International Children Emergency Fund's (UNICEF) data revealed about $90 \%$ of children in the developing countries are undernourished, while $40 \%$ of the world's malnourished live in India. [6] Nearly half of deaths among children are attributable to undernutrition It is reported most of then early 104 million underweight children live in south east Asia and in subSaharan Africa. [6]

Anthropometrics examination is the cornerstone for assessment of health and nutritional status in childhood. [7] Physical measurements like the bodyweight, height, mid upper arm circumference, skin fold thickness of children 
have been widely used to assess the nutritional status of communities. [7] Based on the age, height and body weight, indices such as weight-for-age, height-for-age and weight for height have been used to assess the nutritional status of children. While overnutrition causes obesity among children, undernourished children have classical features of underweight which is low weight for age and it is a reflection of chronic and acute undernutrition. [8] Children with zscores less than-1 with low weight for age are said to be underweight. Children with low height for age are said to be stunted and it measures chronic child undernutrition. Children with low weight for height are said to be wasted and it measures acute undernutrition. Generally children with zscores less than- 3 are said to be severely undernourished. [4]

Healthy developmental milestone of children of all categories depend largely on how well fed they are. Primary school children need good nutrition to improve their mental development and enhance cognitive learning process. [9]

Hunger and undernutrition remain among the most devastating problems facing the majority of the World's poor and needy people, and continue to dominate the health of the World's poorest nations. [8] The tragic consequences of undernutrition especially among children, include, disability, mental retardation, reduced physical growth, vulnerability to infectious diseases and sometimes even deaths. Some $60 \%$ of the 10.9 million deaths each year among children aged under five years in the developing World are associated with undernutrition. [10] Protein energy malnutrition (PEM) remains a major public health problem to such an extent that it is recognized as the second commonest cause of morbidity and mortality in Nigeria. [11]. Micronutrients deficiencies which are required in small quantities in meals for healthy growth among school children have been identified to cause preventable diseases. Iodine deficiency is the greatest single preventable cause of brain damage and mental retardation worldwide, and is estimated to affect more than 700 million people, most of them located in the less developed countries;[12] over 2billion people suffer from iron deficiency anemia. And Vitamin A deficiency remains the single greatest preventable cause of childhood night blindness. [12] Overnutrition which is also malnutrition equally has major public health implications among children especially in view of increased risk of developing diet-related chronic disease later in life. [2]

The epidemic of obesity with its attendant co-morbidities e.g. Heart disease, hypertension, diabetic mellitus etc. Is not a problem limited to developed countries alone. There are reported cases of childhood obesity becoming an emerging problem in developing countries as well. [2]

While most studies have focused on nutritional assessment of preschool children, this study was conducted in Osogbo, Nigeria to bridge the research gap of nutritional assessment of primary school children. The primary aim of the study was to assess the nutritional status of school children in Olorunda Local Government Area of Osun state Nigeria.

\section{Materials and Methodology}

The study was a cross sectional survey conducted at Olorunda Local Government Area of Osun State. Olorunda local government is one of the 30 local government council areas that constitute the present Osun State. It consist of 4 towns, which are Osogbo, Obaile, Obaoke, Ilie as well as many other neighboring villages like Dagbolu, Otaefun, Okeoniti, Obabeedo, Akiribiti, Kobogbogboe, Olueode. The local government area covers a total land of about 600 square $/ \mathrm{kms}$. It shares border on the east with irepodun local government, Surulere local government of Oyo state, Osogbo local government to the west, If elodun/Boripe \& Egbedore local government to the north and the south respectively.

Within the 1991 population census, Olorunda local government had a population of 83,347 people with an annual population growth rate of about $2.83 \%$. There are public, private primary and secondary schools in the study area. There are as well Primary, Secondary and Tertiary health facilities located in the study area.

\subsection{Study Population}

Reference population: population of Olorunda LGA. Target population: School age children

Study population: Pupils of Public Primary schools

\subsection{Sample Size Determination}

Sample size was determined using the fisher's formula $>10000$

$$
\mathrm{N}=\mathrm{z}^{2} \mathrm{pq} / \mathrm{d}^{2}
$$

Where $\mathrm{z}=$ standard normal deviate of 1.96 at $95 \%$ confidence interval.

$\mathrm{P}=$ prevalence of $50 \%$ was used.

$\mathrm{q}=1.0-\mathrm{p}$

$\mathrm{d}=$ degree of accuracy (precision) set at 0.05

$\mathrm{N}=1.96^{2} \times 0.5 \times(1.0-0.5) / 0.05^{2}$

$\mathrm{N}=3.84 \times 0.5 \times 0.5 / 0.0025$

$\mathrm{N}=0.96 / 0.0025$

$\mathrm{N}=384$

Therefore the calculated sample size is 384 ., To make allowance for non response rate a $10 \%$ of calculated sample size was added which was 422 , but the sample was adjusted to 487 .

\subsection{Sampling Technique}

Stage 1: Simple random sampling method was employed by balloting to select 11 primary schools out of 44 , of which 8 were public while 3 were private.

Stage 2: Respondents were selected from each class with a proportionate sample size through simple random sampling by balloting.

\subsection{Research Instruments}

The instrument used for the study was an interviewer 
administered semi-structured questionnaires administered to the primary school pupils selected as respondents. The questionnaires were in four sections which addressed socio demographic characteristics, educational history, nutritional assessment using anthropometry, as well 24 hours nutritional recall. The anthropometric measurements were Height, Weight, Weight for age, Height for age.

The choices of anthropometric measurements were based on variables related to growth of children. The equipments used to obtain these measurements were Tape measure and weighing bathroom scale (Harsons).

Measurements of variables.

\section{Hour nutritional recall}

Nutritional status assessment using 24 hour dietary recall was graded in to poor, fair, and good nutrition based on the following method each meal taken with one of the five basic elements of nutrients was scored as 1 . Elements of nutrition such as carbohydrate, proteins, fats and oil, vitamins and essential minerals were used. Each meal that contained onlylelement of nutrient was scored as 1 , each meal that contained 2 elements of nutrients was scored as 2, each meal that contained 3 elements of nutrients was scored as 3 , and each meal that contained 4 elements of nutrients was scored 4 , and each meal that contained all the five elements of nutrients was scored as 5. A total score in the last 24 hours less than 9 was graded as poor, equal to 9 as fair, and greater than nine as good.

Anthropometric indices.

Weight, height values were related to age and compared with World Health Organisation child growth standards for weight-for-age, height-for-age $\mathrm{z}$ scores. Children were classified as underweight, stunted if the $\mathrm{Z}$ score for weight for age and height for age were less than -2 standard deviation below the WHO median of standards for age and sex. [13] Overweight and obesity were taken as z-scores of $+2 \mathrm{SD}$ and $+3 \mathrm{SD}$, respectively. These are standard parameters for assessing undernutrition and overnutrition among children. Harson's bath room salter scale $(120 \mathrm{Kg}$ capacity) was used for the measurements of the weights of pupils. The scale was maintained at zero point reading prior to weighing each child. Each child was made to stand on the platform of the scale without shoes, hands by the sides and head held erect. Reading was taken to the nearest $0.1 \mathrm{~kg}$. The height of the children were obtained using height metre tape rule. [13] They were made to stand erect without footwears, with feet parallel, heels together, arms hanging by the sides and the buttocks, shoulder and back of the head touching the metre rule. Readings were taken to the nearest $0.1 \mathrm{~cm}$.

Z- score measurements of nutritional status of pupils using weight, height as indicators.

$\leq-3$ standard deviation $=$ Severe undernutrition

$\leq-2$ standard deviation $=$ moderate undernutrition

$\geq 1$ to $\leq 2$ standarddeviation $=$ Good nutrition.

$\geq 2$ to +3 standard deviation is overweight or obesity [4].

\subsection{Data Collection and Analysis}

Quantitative data collection method was used to elicit information from respondents. The data generated from the questionnaires were checked manually for errors and analysis was done using Statistical Package for Social Sciences (SPSS). Chi-square was used to determine the statistical significance of the difference between relevant variables. Results were presented using frequency tables, figures and charts.

Inclusion criteria: All primary school children whose parents gave consent were recruited for the study

Exclusion criteria: Pupils who were ill were excluded from the study.

3.9 Study Limitation: Inability to conduct hematological and biochemical assessment due to the socio-cultural barriers to obtaining blood and other body samples. Difficulty in obtaining accurate information from pupils in the lower classes i.e. primaries 1 and 2 pupils-due to their relatively young ages. Financial resources limitation

Permission was sought from the chairman of State Primary Education Board as well as informed consent obtained from the heads of schools used for the study. Consent was obtained from the parents of the school pupils and they were free to opt out of the study at any stage. Parents were assured of confidentiality and that the data collected was strictly for research purpose.

\section{Results}

Table 1. Socio-demographic characteristics of respondents.

\begin{tabular}{|c|c|c|}
\hline Variables & N (487) & $(\%)$ \\
\hline \multicolumn{3}{|l|}{ Ages (years) } \\
\hline$<5$ & 50 & 10.3 \\
\hline $6-10$ & 352 & 72.3 \\
\hline $11-15$ & 83 & 17.0 \\
\hline$>16$ & 2 & 0.4 \\
\hline \multicolumn{3}{|l|}{ Sex } \\
\hline Male & 226 & 46.4 \\
\hline Female & 261 & 53.6 \\
\hline \multicolumn{3}{|c|}{ Father's occupation } \\
\hline Unemployed & 14 & 2.9 \\
\hline Unskilled & 174 & 35.7 \\
\hline Skilled & 179 & 36.8 \\
\hline Professional & 120 & 24.8 \\
\hline \multicolumn{3}{|c|}{ Mother's occupation } \\
\hline Unemployed & 30 & 6.2 \\
\hline Unskilled & 286 & 58.7 \\
\hline Skilled & 95 & 19.5 \\
\hline Professional & 76 & 15.6 \\
\hline \multicolumn{3}{|l|}{ Birthorder } \\
\hline $1^{\text {st }}$ & 118 & 24.2 \\
\hline $2^{\text {nd }}$ & 112 & 23 \\
\hline $3^{\text {rd }}$ & 99 & 20.3 \\
\hline $4^{\text {th }}$ & 100 & 20.5 \\
\hline Other & 58 & 11.9 \\
\hline \multicolumn{3}{|l|}{ Caregiver } \\
\hline Parents & 441 & 90.6 \\
\hline Guardian & 46 & 9.4 \\
\hline
\end{tabular}

Table 1 shows the socio demographic characteristics of the pupils. Most of the pupils fell within the age range of 6-10 years $(72.3 \%)$ with a mean age of 8.4 and the modal age of 10.0. More females were studied representing about $53.6 \%$. 
There was almost the same ratio of distribution between skilled and unskilled occupation of respondents' fathers. (179, $36.8 \%$ and $174,35.7 \%)$; the mothers $(58.7 \%$ ) of most pupils were unskilled workers. Almost half of the respondents $(47.2 \%)$ were of the $1^{\text {st }}$ and $2^{\text {nd }}$ birth order-while the rest $53.8 \%$ above the $2^{\text {nd }}$ birth order. About $90.6 \%$ of pupils lived with their parents.

Table 2. Educational history of respondents.

\begin{tabular}{lll}
\hline Variables & $\begin{array}{l}\text { Frequency } \\
(\mathbf{N}=\mathbf{4 8 7})\end{array}$ & $\begin{array}{l}\text { Percentage } \\
(\mathbf{\%})\end{array}$ \\
\hline $\begin{array}{l}\text { Present Class of Pupils } \\
\text { Primary1 }\end{array}$ & 118 & 24.2 \\
Primary2 & 112 & 23.0 \\
Primary3 & 99 & 20.3 \\
Primary4 & 100 & 20.5 \\
Primary5 & 58 & 11.9 \\
$\begin{array}{l}\text { Ever Changed School } \\
\text { No }\end{array}$ & & \\
Yes & 238 & 48.9 \\
$\begin{array}{l}\text { Reasons for above } \\
\text { Financial constraint }\end{array}$ & 249 & 51.1 \\
$\begin{array}{l}\text { Distance constraint } \\
\text { Poor academic }\end{array}$ & 123 & 49.4 \\
$\begin{array}{l}\text { Performance/dissatisfaction with teaching } \\
\text { Dissatisfaction with social issues / No }\end{array}$ & 57 & 22.9 \\
reason / don't know & 31 & 12.4 \\
School type & 38 & \\
$\begin{array}{l}\text { Public } \\
\text { Private }\end{array}$ & & \\
\hline & 401 & 82.3 \\
\hline
\end{tabular}

Table 2 revealed that $24.2 \%$ and $23 \%$ respectively of respondents were in primary 1 and primary 2 classes. The least number of respondents $(11.9 \%)$ came from primary 5 . About $51.1 \%$ of the pupils had ever changed schools and the majority of these $(49.4 \%)$ were due to financial constraints.

Table 3. Assessment of nutritional status using anthropometric indices.

\begin{tabular}{lll}
\hline Variables & Frequency $(\mathbf{N}=\mathbf{4 8 7})$ & $\mathbf{( \% )}$ \\
\hline Height for age & & \\
Above normal & 119 & 24.4 \\
Appropriate & 48 & 9.9 \\
Below normal (stunted) & 320 & 65.7 \\
Weight for age & & \\
Above normal & 81 & 16.6 \\
Appropriate & 43 & 8.8 \\
Below normal (underweight) & 363 & 74.5 \\
\hline
\end{tabular}

Table 3 showed that most of the pupils (65.7\%) fell below the standard height for age (stunting) which is an indicator for malnourished children. Respectively $9.9 \%$ and $24.4 \%$ of pupils had average and above expected height for age. Most pupils $(74.5 \%)$ had their weight for age below normal, which is an indicator of undernutrition due to weight loss arising from poornutritionalstatus.

Table 4. Assessment of nutritional status by 24-hour dietary recall of respondents.

\begin{tabular}{lll}
\hline Nutritional assessment & Frequency N (487) & (\%) \\
\hline Poor dietary intake & 245 & 50.3 \\
Fair dietary intake & 115 & 23.6 \\
Adequate dietary intake & 127 & 26.1 \\
\hline
\end{tabular}

Table 4, above shows the 24-hour dietary recall. $50.3 \%$ of the respondents had poor nutrition scores. $26.1 \%$ had adequate nutrition scores.

Table 5. Nutritional assessment based on 24 hrdietary recall.

\begin{tabular}{lllll}
\hline \multirow{2}{*}{ Sex } & \multicolumn{3}{l}{ Nutritional Status } & \multirow{2}{*}{ Total (\%) } \\
\cline { 2 - 4 } & POOR (\%) & FAIR (\%) & GOOD (\%) & \\
\hline Male & $119(52.7)$ & $43(19.0)$ & $64(28.3)$ & $226(46.3)$ \\
Female & $126(48.3)$ & $72(27.6)$ & $63(24.1)$ & $261(53.7)$ \\
Total & $245(50.3)$ & $115(23.7)$ & $127(26.0)$ & $487(100.0)$ \\
\hline
\end{tabular}

Chi-square $=5.032 \mathrm{p}$-value -0.081

Table 5, shows that the male respondents had poorer nutritional score $(52.7 \%)$ than the female respondents $(48.3 \%)$; also that the male respondents had a better nutritional score $(28.3 \%)$ than the female respondents $(24.1 \%)$.

\section{Discussion and Conclusion}

The study provides anthropometric data on nutritional status among selected primary school pupils in Nigeria. Good nutritional status of children is a strong indicator of the overall wellbeing of children. In this study a total of 487 pupils were interviewed and of these, less than haif were males while barely above half were females. This was inconsonance with a survey report of the Nigerian demographic and health surveys (NDHS2003 [14], where a Net Attendance ratio (NAR) of 0.9 to 1 was obtained between male and female pupils whose nutritional status was studied. In this study more female pupils were interviewed having the male to femal e ratio as 1:1.2 respectively.

The age of the pupils ranged from 4 to 16 years with almost about three quarter falling within the 6 and 10 year age group. This is in agreement with a study on nutritional status conducted among primary school children whose age range was between 6 and 10 years in Lagos. [15] Above half of the pupils were children of parents with unskilled jobs who are most likely in the low socioeconomic class. This was likely to influence their food security status which could have affected the nutritional status in the study area. This corroborates a previous study reported by Smulders Mark etal who observed the challenge of food security among unskilled workers in the Mediterranean which affected the nutritional status of the household including the children. [16]

Most of the school children studied, lived with their parents while less than ten percent live under caregivers who were not direct parents of the children. In a case study of family effect on academic performance of primary school pupils, it was observed not all children who live with their parents have positive performance in their academic work especially those with poor nutritional status. [17] While parental role is expected to influence children positively, in some instances the reverse is the case.

Above half of the studied population were from third birth order and above. This is similar with a survey in Sri Lanka that reported high birth order in a study conducted to 
assess nutritional status on preschool and school children. [18] Factors reported to be responsible for high undernutrition rate in primary school children was high birth order among others such as maternal employment, high number of siblings. [18]

In this study the high number of birth order no doubt would have affected the nutritional status of the pupils. High birth order is commoner in developing countries and associated with low income earners. In some cases, a man has multiple wives and several children even when he is of low socioeconomic status.

Barely above half of the respondents reported changing schools, while about half reported financial constraints as reason for changing school. Socioeconomic status is a strong determinant of good academic performance of pupils as well as their nutritional status. This is in consonance with the report of the study on nutritional status and correlated socioeconomic status factors among school children in Sri Lanka. [19]

Living in small houses, large number of family members, low monthly income and maternal employment were significantly associated with undernutrition among school children studied in SriLanka. [19]

About two third of respondents were reported to be stunted, having low height for age with $\mathrm{Z}$ score below normal value. This is not exactly similar to a study that examined the prevalence of undernutrition in south eastern area of Nigeria which reported about half of the school children to be stunted. [20]

This is a clear indication of the prevalence of chronic undernutrition among the pupils in the study area. About three quarter of the pupils studied had low weight for age which is an indication of underweight among malnourished children. This is not in consonance with a similar study conducted in south eastern Nigeria that reported less than half of the respondents developing low weight for age which is undernutrition [20].

In this study about one quarter of respondents reported adequate dietary intake through assessment of 24 hour dietary recall. This is in consonance with a study in Kenya that examined dietary recall among school children aged 8 and 16 age that reported low adequate dietary intake in the 24 hours assessment. Nutritional status assessed by dietary recalls revealed most of the root causes of undernutrition among children. [21]

The nutritional assessment of the primary school pupils in the study area is a reflection of the challenges poor nutritional status among children in Nigeria being a developing country. The challenge of poverty, food insecurity, intertribal conflicts and insurgency have worsen the food situation crisis in the country especially in the northern part of the country where most of these factors are predominant. Strong political will is needed to improve the agricultural sector and address some of these factors itemized. What happens in Nigeria may not be too different from several other developing countries.

This study concluded that a significant percentage of the pupils in the study areas were assessed to have poor nutritional status despite the various intervention programmes of nonGovernmental and Governmental organizations. This calls for more proactive actions from relevant stakeholders address the issue of food security in the area.

\section{Competing Interests}

There was no competing interest declared throughout the course of the research worl.

\section{References}

[1] Black RE, Victor CG, Walker SP, Bhutta ZA, Christian P, Deonis M. et al. (August2013)."Maternal and child undernutrition and overweight in low-income and middleincome countries". Lancet. 382 (9890): 427-451. doi: 10.1016/S0140-6736(13)60937X.PMID23746772.S2CID12237910.

[2] Asmare, B., Taddele, M., Berihun, S. et al. Nutritional status and correlation with academic performance among primary school children, northwest Ethiopia. BMC Res Notes 11, 805 (2018). https://doi.org/10.1186/s13104-018-3909-1.

[3] Moseley, W. G. \& Battersby, J. 2020. The Vulnerability and Resilience of African Food Systems, Food Security and Nutrition in the Context of the COVID-19 Pandemic. African Studies Review, 63 (3).

[4] World Health Organization. WHO growth standards for children 5-19years. 2007. Linkhttp://www.who.int/childgrowth/standards/en/.

[5] Daniel Goon, Abel Toriola, Brandon Shaw et al. Anthropometrically determined nutritional status of urban primary school children in Makurdi, Nigeria. BMC Public Health 2011: 11: 769.

[6] UNICEF Global nutrition reports. Press releases. 2018. http:www.UNICEF.org.pres sreleases.2018global- $n$.

[7] Kyle Casadei; John Kiel. Anthropometric Measurement. 2020. University of Florida College of Medicine-Jacksonville.

[8] Kassie, G. W., Workie, D. L. Determinants of under-nutrition among children underfive years of ageing Ethiopia. BMC Public Health 20, 399 (2020). https://doi.org/10.1186/s12889020-08539-2.

[9] Al-Ameri RJK, Abdalhamid WG (2018) Nutritional Assessment of Schools' Children of Six Years Oldin Al-Dora Family Medical Center in Baghdad/Iraq. Fam Med Med Sci Res 7: (223) 4, 5. doi: 10.4172/2327-4972.1000223.

[10] Olaf M, Michael K (2005) Malnutrition and health in developing countries; Canadian medical Association Journal A173. Link: https://bit.ly/3ia2ZlB.

[11] IloriIniabasi Udoh, Ikobah Joanah Moses. A Comparison of Three Age-based Formulae of Estimating Weight in Nigerian Children. American Journal of Medical Sciences and Medicine. 2015; 3 (2): 24-27. doi: 10.12691/ajmsm-3-2-4.

[12] WHO/UNICEF/Internationl Council for the Control of Iodine Deficiency Disorder. Progress towards the elimination of iodine deficiency disorders (DD). Geneva, World Health Organization. 1999 (document WHO/NHD/99.4). 
[13] Ferreira, H. d. S. Anthropometric assessment of children's nutritional status: a new approach based on an adaptation of Water low's classification. BMC Pediatr 20, 65 (2020). https://doi.org/10.1186/s12887-020-1940-6.

[14] National demographic health survey of Nigeria. 2003 pg. $163-$ 168.

[15] Abidoye RO, Akande PA. (2000) Nutritional status of public primary school children: a comparison between an upland and riverine area of Ojo LGA, Lagos State Nigeria Nutrition and health journal. 2000, $14 \quad$ (4): $225-40$ doi: $10.1177 / 026010600001400404$.

[16] Mark Smulder, Mohamed AW-Dabir, Kate Dunn, Rene Verduijn. Food security and nutrition in the southern and eastern RIM of theme diterraneanbasin. 2013.

[17] Anonymous, 2017, The Family Effect on Academic Performance in School. A Case Study of selected Schools in Kabale District, Munich, GRIN Verlag, https://www.grin.com/document/384998.
[18] Galgamuwa, L. S., Iddawela, D., Dharmaratne, S. D. et al. Nutritional status and correlated socio-economic factors among preschool and school children in plantation communities, Sri Lanka. BMC Public Health 17, 377 (2017). https://doi.org/10.1186/s12889-017-4311.

[19] Lahiru Sandaruwan Galgamuwa, DevikaIddawela, Samath D Dharmaratne, GLS Galgamuwa. Nutritional status and correlated socio-economic factors among preschool and school children in plantation communities, Sri Lanka 2017. 17 (1): 377. doi: 10.1186/s12889-017-4311-y.

[20] Ayogu, R. N. B., Afiaenyi, I. C., Madukwe, E. U. et al. Prevalence and predictors of under-nutrition among school children in a rural South-eastern Nigerian community: across sectional study. BMC Public Health 18, 587 (2018). https://doi.org/10.1186/s12889-018-5479-5.

[21] Sable, Sylvia Krivanek (2013). Validity of 24-Hour Dietary Recall in Children Age 8 to16 in Western Kenya. Master's thesis, Duke University. Retrieved from https://hdl.handle.net/10161/8276. 